\title{
Deontologization of culture and identity transformation in the context of a consumer society
}

\author{
Liudmila Babakhova* \\ Don State Technical University, 344006, Rostov-on-Don, Russia
}

\begin{abstract}
The article substantiates the point that deontologization of culture as a process of collapse of principal value foundations resulted in the absence of stable worldview guidelines and in the establishment of principles of relativism and pluralism. Cultivation of an unlimited choice in the absence of a value-semantic hierarchy, which is characteristic of the Western European culture organized around mass consumption, has led to the inability to create stable identification models. As a result, one of the main problems of contemporary society has become the loss of a stable, holistic identity by a person. The instability of existence, the loss of valuesemantic foundations assigned a task of constant self-construction of identity to a person. The principle of consumption as the dominant feature of modern times characterizes an individual lifestyle of a person. In the process of the historical transition to a consumer society, the source of identity formation shifted from the labour sphere to the sphere of consumption, leisure, entertainment. Self-identification of a person is closely related to consumerism. To a large extent, identity began to be determined by the consumer role rather than the class affiliation. As a result, consumption has become one of the main sources of self-identity. In consumer culture, identity is deprived of a fixed centre and appears as an infinitely transformed, mobile thing shifting into the sphere of individual needs and desires; conscious feeling of oneself as a holistic identity becomes unclaimed. The ideology of consumption determines the lifestyle, preferences and character of a person. The media, which are the main identification tools in modern popular culture, offer models and patterns of behaviour that contribute to the formation of a consumer engaged in the search for the quality of his/her individual life.
\end{abstract}

\section{Introduction}

There are various descriptions of modern times as a consumer society (Baudrillard J., 2006, Jameson F., 2000, Ritzer G., 2011, Featherstone M., 1991), an era of narcissism (Lipovetsky G., 2001, Lasch C., 1979), an individualized society (Bauman Z., 2008), but all

\footnotetext{
*Corresponding author: babahova_1@mail.ru
} 
of them, one way or another, recognize the problematic nature of a person's identity. The fundamental transformations associated with the development of a market economy, the change in the nature of labour, the increase in free time and the widespread dissemination of media and information technology have transformed the structure and nature of consumption. The situation of uncertainty caused by an unprecedented growth of sociocultural and material-technical changes resulted in the loss of a person's stable, given identity as the original being that determines personality.

The purpose of this article is to provide a meaningful analysis of the transformation of a person's identity in deontologized culture of the Western European consumer society. The purpose determined the solution of the following tasks: to consider the sources of the deontologization process, to analyse the specificity of personality identification in a consumer society, to determine the influence of consumer ideology on identification processes, dynamics and stability of identity.

Research methods: The study of identity transformation in the context of deontologization of culture is based on the use of such philosophical principles and general scientific methods as the principle of objectivity, the method of comparative analysis and synthesis, analogy and scientific generalization.

\section{Concept and meaning of deontologization of culture}

The modern Western culture found itself in a situation of loss of value foundations. Deontologization of culture turned into a crisis of personality, the loss value foundations that ensure integrity. Deontologization is expressed in the loss of the ontological basis and the purport of existence by culture. The loss of a value-based core that once provided integrity forms the basis of the identity crisis. Values have lost their ontological status.

The image of a person has lost its integrity. Identification does not eliminate partiality any more. The place of the only, true self was taken by potential self, which has no roots either in culture, or even, ultimately, in its own body. A "person without properties", a person without a rigid identification, who can be anyone, entered the stage of history.

The loss of a holistic identity is associated with the consistent destruction of principal foundations of Western European culture. As a result, the ideas of a vertical value hierarchy that prevailed in culture were supplanted by the idea of a horizontal progress, which allowed us to consider the conscious self-creation of a person as overcoming the past and continuing the biological evolution. All this made it possible to believe that there were many different but equivalent versions of a human life. The principle of uniformity and the search for uniformity have been replaced by the value of moving towards universal diversity. The rejection of fundamental principles cementing the culture has made viable the radical pluralism that characterizes modern times.

The transcendental value dimension lost by culture resulted in the establishment of a mosaic, fragmented culture in which there is no worldview unity. The collapse of the values classical system gave rise to a diverse disorder of meanings.

\section{Sociocultural foundations of the deontologization process}

Sociocultural foundations of the deontologization process are largely associated with the establishment of Western individualism and the formation of a new self-identity of a person. The background of modern individualism originates in the culture of the Renaissance, a symbol of which is a free person. At the Renaissance, the transformation of worldview guidelines began, marking the transition to the establishment of new capitalist relations. Changing the type of culture meant the transformation not only of the image of 
the world but also the person's self-awareness, attitude to reality, value-based and worldview guidelines.

This is the time of birth of individuality, in which the new economic reality of European history finds its expression. Human subjectivity is endowed with autonomy and independence capable of developing ethical standards and establishing the purport of one's own life.

New European individualism was turned to the sphere of cultural self-awareness, in which each person had to find the highest values for himself/herself and pass the entire previous cultural and historical tradition through the personality. "Indeed, from now on, even if a person chooses a confessional position, he/she exists in a world where there is no total, common for all, single and mandatory position; therefore, in any case, this is his/her personal position" (Batkin L.M., 1989, p.30).

By the 20th century, Western individualism has come a long way in social transformation from affirming the inherent value of a person to egocentrism. The holistic personality of the Renaissance was reborn into a hedonistically inclined person, oriented by the bourgeois consumer spirit. European individualism made an emphasis on the material being of a person, giving rise to the destruction of the human "self". The spiritual state of modern Western culture indicates the on-going deep transformation of key human values, the conditions of existence and life goals. Significant changes in the value and worldview focus were largely determined by the break from the traditional Protestant ethics of individual labour, abstention and zeal, and the transition to the so-called hedonistic consumer society. Orientation to work, frugality, and moderation was replaced by a focus on entertainment, wastefulness, and thirst for new things.

\section{Transformation of identity in the context of a consumer society}

Individualism, which means liberation of a person from various social groups, awareness of his/her individuality, has degenerated into the right of self, the right to achieve his/her own success. The sense of ownership has spread to social status, knowledge, image of one's own self, all this begins to be perceived as a certain thing that we possess and that forms the basis of our self-awareness. The identification process began to be carried out through possession of things, people, and sensations.

If at the early stages of modern society, as a rule, the social class was the main source of identity, in modern times, individual experience was the basis for the formation of identity.

The loss of identity as a feeling of one's own uniqueness and singularity, a feeling of integrity and continuity is characteristic of a person who feels like a product with a certain personality set corresponding to one of the proposed standard patterns. Along with the loss of a feeling of the integral self, a person loses the feeling of identity, in this case, as E. Fromm points out, "each person is a "package" in which several aspects of his exchange value are blended into one: his "personality" (Fromm E., 2006). In this case, the person begins to be understood in terms of those qualities and characteristics with which you can more successfully invest yourself, exchange for a higher cost, and, if necessary, get rid of old feelings and habits.

A plastic person, deprived of properties, claimed by modern culture, must be able to try on different roles depending on the situation. The problem of self-awareness is removed from the agenda; the person is busy satisfying the desires. Self turns into a system of desires and their immediate satisfaction; on the other hand, desires are created artificially using the market mechanism. "The world is one great object for our appetite, a big apple, a big bottle, a big breast; we are the sucklers, the eternally expectant ones, the hopeful ones - and the eternally disappointed ones" (Fromm E., 2006). 
The process of deontologization of culture is associated with the emergence of morality focused on self-satisfaction. In The Cultural Contradictions of Capitalism, Daniel Bell shows that "Protestant ethic as a social reality and a life-style for the middle class was replaced by a materialistic hedonism, and the Puritan character - by psychological eudemonism" (Bell D., 1976, p.74). Consumer culture stimulates the ethics of hedonism.

Commodity production and consumption lead to the transformation of the person's perception of not only himself/herself, but also the surrounding reality. The emerging illusory world makes the distinction between fantasy and reality more difficult. The consumer finds himself/herself in a world that exists to satisfy or dissatisfy desires. In this regard, G.L. Tulchinsky discusses the on-going marketization of values, which has spread to all areas of social life "and gave rise to popular culture with its transformation of the hierarchy of transcendental values into sectors of a market economy" (Tulchinsky G.L., 2007, p. 195). A variety of lifestyles are offered to people on storefronts, and a person can become a part of it if certain goods are purchased.

Things become a status symbol, taking a certain place in the identification process. Buying certain things, a person gains a new identity, experiencing the pleasure in the purchase and getting a sense of self-worth. The identification process merges with the principle of ownership.

In consumer culture, identity appears as an infinitely transformed, mobile thing, associated with the purchase of new goods. Advertising takes a leading role in the production of new meanings, sets standards and patterns of behaviour. Creation of a product image that helps people navigate the sea of standardized goods is of paramount importance in this process. "In this regard, a brand actually becomes a social myth - a way and means of human comprehension of reality and orientation in it" (Tulchinsky G.L., 2007, p.197).

Creating the image of a product, advertising gives value to invented images, affecting the moral aspects of public life.

The images and meanings of consumer culture began offering a person an identity corresponding to them. A person is no longer attached to the object itself, but only to that ideal image, the ideal identity that the object carries. A person turns into a consumer of signs and images.

As J. Baudrillard points out, the logic of the product governs "culture, sexuality, human relations ... all functions and needs are objectified and manipulated under the sign of profit ... everything is a performance, that is, presented, produced, organized into images, into signs, into consumed models" (Baudrillard J., 2006, p. 240).

Countless equivalent "life images" appear, each of which has the right to coexist simultaneously.

Deprived of a fixed centre, the self-identification of a person becomes unstable and blurred. With the destruction of the once unshakable ideas about value guidelines, a person faces an independent choice of the necessary - from his/her point of view - model of behaviour.

However, decentering of moral standards and patterns of behaviour, the equivalent coexistence of different value guidelines actually makes pointless the search for guidelines in the process of self-construction of identity.

The life space itself becomes blurred. The unpredictability of life, the absence of stable ideals, the loss of the assigned social role poses a challenge of constantly constructing one's own self.

Along with the loss of a feeling of integrity and continuity and a feeling of uniqueness and singularity, the feeling of identity disappears; identity is replaced by a free set of personal qualities collected through consumption of goods and images. The idea of selfrealization, suggesting some purpose, is replaced by the idea of experimental self-creation. 
The implementation of consumer preferences results in equating the self with the ability to play many roles and accept an infinite variety of freely chosen identifications. The merry ethics of leisure, hedonism and self-realization approved the cult of consumption with its immediate satisfaction. Popular consumer culture sets new meanings that contradict previous traditions. The ideals of self-control, zeal, frugality, rational desire for accumulation and wealth were supplanted by the search for pleasure and self-actualization. In a society focused on increasing consumption, the mind has become incapable of limiting the desire for pleasure. Immediate satisfaction of every desire gained the right to be realized regardless of its value identification.

\section{Conclusion}

Identity is a problem of modern times, the history of which is inseparably associated with the rise of Western individualism that provides the awareness that the conditions of modern life require self-determination of a person regardless of the inherited forms of thinking and behaviour. However, a new type of worldview that is emerging in modern times focuses solely on promoting self-care, in which the individual self is affirmed as the only good.

This self-absorption defines the moral ground of the modern society, in which the once prevailing idea of conquering nature gave way to hedonism and the endless search for selfrealization. In a fragmented world of consumption, identity becomes isolated from social structures and cultural traditions and shifts to the sphere of individual needs and desires. The modern period is characterized by fundamental changes in the process of identity formation, in which the orientation toward consumption, the pursuit of personal success and material well-being become the dominant attitudes. Transforming from the immediate satisfaction of needs into one of the main elements of socialization, consumption changes the social structure of the modern society, determining the lifestyle, aspirations and character of a person.

Relativism and the lack of stable worldview guidelines that characterize the current situation, the cultivation of unlimited choices result in inability to create sustainable identification models.

A specific environment is formed under the existing worldview paradigm with the corresponding ideology approving the paramount importance of satisfying individualized needs.

For further research, it would be interesting to determine the main causes of the worldview crisis that entailed an identity crisis, analyse the value transformations in the context of development of a consumer society and determine the degree of influence of a consumer culture on the formation of a person's identity.

\section{References}

1. L.M. Batkin, The Italian Renaissance in the Search for Identity (Nauka, Moscow, 1989).

2. J. Baudrillard, The Consumer Society: Myths and Structures (Respublika; Kulturnaya Revolutsiya, Moscow, 2006).

3. Z. Bauman, Liquid Modernity (Piter, St. Petersburg, 2008).

4. D. Bell, The Cultural Contradictions of Capitalism. Basic Books (Inc., Publishers. New York, 1976).

5. M. Featherstone, Consumer Culture and Postmodernism (Newbury Park; New Delhi: Sage Publications, London, 1991). 
Fromm,

Healthy

Society, http://royallib.com/book/fromm_erih/zdorovoe_obshchestvo.html (access date: 21.07.2019).

7. F. Jameson, Postmodernism and Consumer Society, Logos, 4, 63-77 (2000).

8. C. Lasch, The Culture of Narcissism. American Life in an Age of Diminishing Expectations (New York, Norton, 1979).

9. G. Lipovetsky, The Era of Emptiness. Essays on Contemporary Individualism (Vladimir Dal, St. Petersburg, 2001).

10. G. Ritzer, The McDonaldization of Society (Praxis, Moscow, 2011).

11. G.V. Sorokin, T.I. Eroshenko, A.V. Fedoseenkov, A.V. Malyshev, Postmodern and Social Problems of Cities, Materials Science Forum, 931, (2018).

12. G.L. Tulchinsky, Marketization of Humanism, Chelovek.RU, 3, 194-218 (2007). 